Egyptian

Orthodontic Journal

\title{
DENTOALVEOLAR CHANGES OCCURING WITH CORTICOTOMY ASSISTED SLOW PALATAL EXPNSION
}

\author{
Abu-bakr Reda Bakr*, Abbadi Adel El kady **, \\ Shrief samier morcos***, Tamer Abd Elbari Hamed**** \\ ABSTRACT
}

Background: Maxillary expansion in skeletally mature patients with fused mid palatal suture and circum maxillary resistance makes the conventional non-surgical expansion methods insufficient. Aim: To evaluate the dentoalveolar changes occurring with corticotomy assisted SME. Methods: Sixteen patients (4 males and 12 females) requiring maxillary expansion (mean age:19 years; range: 14-24 years) were divided into two groups: Group A: included 10 patients subjected to buccal alveolar corticotomy before SME and Group B: included 6 patients who had only SME.CBCT images were taken at T1(before) and T2 (after). Inter molar (IMW) and Inter premolar widths (IPmW) as well as root angulations (RA) and buccal bone thickness (BBT) at the level of first molars and first premolars were recorded. $\mathcal{T}$-tests (paired, student) determined the significance $(\mathcal{P} \leq 0.05)$ performed to evaluate the effect of treatment within and between each group. Results: Expansion achieved in corticotomy group was $5.900 \pm 0.348 \mathrm{~mm}$ for $I M \mathcal{W}$ and $5.000 \pm 0.258 \mathrm{~mm}$ for IPmW, and was significantly higher than SME only group. Root tipping showed no statistical

\footnotetext{
* Master Degree student, Orthodontics dept, Faculty of dentistry, Suez Canal University

${ }^{* *}$ Professor , Orthodontics dept, Faculty of dentistry, Suez Canal University

${ }^{* * *}$ Lecturer, Orthodontics dept, Faculty of dentistry, Suez Canal University

***** Assistant professor, Oral and maxillofacial dept, Faculty of dentistry, Suez Canal University Highlights : Corticotomy, SME, Dentoalveolar , CBCT
} 
Egyptian

Orthodontic Journal

significant differences between 6oth groups. Buccal bone thickness decreased significantly in both groups with no statistical significant differences between both groups. Conclusions: Corticotomy assisted expansion is an efficient and safe treatment and shows a significant increase in IMMW and IPmW compared to SME only. Son-significant differences in root angulations between the two groups were noted suggesting that the expansion in corticotomy group was more translatory movement than tipping. The corticotomy procedure does not cause a different response of buccal bone compared to SME onfy group.

\section{INTRODUCTION}

Transverse maxillary constriction is frequently seen in adolescents and adults due to multifactorial etiology ${ }^{[1,2]}$ leading to decrease of the nasal permeability, bilateral dental maxillary crossbite, compromising esthetics, occlusal stability, and normal mouth functioning ${ }^{[3]}$.Therefore, early treatment is necessary to establish craniofacial equilibrium and myofunctional correction to favor normal growth and development ${ }^{[4]}$. Maxillary expansion before the pubertal peak exhibits significant and more effective long-term changes at the skeletal level, but when treatment is performed after the pubertal growth spurt, maxillary adaptations to the expansion therapy shift from the skeletal level to the dentoalveolar level ${ }^{[5]}$. This change is corresponding to the increase of interdigitations between suture processes which become heavy to the extent that a separation of the two halves of the maxilla would not be possible without fracturing the interdigitated processes ${ }^{[6]}$, which makes the correction of maxillary constriction in a skeletally mature patient more challenging ${ }^{[7]}$. The conventional nonsurgical method of slow expansion used in adults is problematic, limited, and inefficient as it takes a long time and might compromise periodontal health if done beyond a few millimeters ${ }^{[8]}$. The development of corticotomy assisted orthodontics has provided new solutions to many limitations in the orthodontic treatment of adults. Köle in 1959 suggested that the disrupting of continuity of the cortical layer of 
Egyptian

Orthodontic Journal

bone leads to moving segments of bone in which the teeth were embedded and allows these outlined blocks of bone to be moved rapidly and somewhat independently of each other ${ }^{[9]}$. Wilcko developed the current technique named Accelerated Osteogenic Orthodontics (AOO) ${ }^{[10]}$ or Periodontally Accelerated Osteogenic Orthodontics $(\mathrm{PAOO})^{\mathrm{TM}}{ }^{[11]}$ to enhance tooth movement, subsequently, reducing treatment time via inducing cortical bone injury through linear cutting (corticotomy) and then performing orthodontic treatment. Frost ${ }^{[12]}$ found a direct correlation between the severity of bone injury and the intensity of its healing response, which occurred mainly as a reorganized activity and accelerated bone turnover at the surgical site. This type of healing response was named "Regional Acceleratory Phenomenon" (RAP) ${ }^{[13]}$. Corticotomy assisted expansion is considered an optimal way to treat mild to moderate maxillary transverse deficiency in adults with greater stability and without compromising periodontal health. Studies about corticotomy assisted expansion like those done by Mossaz et al. ${ }^{[14]}$, Wilcko et al. ${ }^{[1]}$ and Hassan et al. ${ }^{[15]}$ showed the efficiency and safety of such technique in treatment of maxillary constriction and posterior crossbite either unilateral or bilateral in adult, but they did not give full explanation about the dentoalveolar and skeletal changes associated with this type of treatment. The aim of this study is to evaluate the dentoalveolar changes occurred with SME assisted with buccal alveolar corticotomy.

\section{Methods:}

Sixteen patients (12 females and 4 males) requiring maxillary expansion therapy as part of their comprehensive orthodontic treatment were included in this study. All treatment was started after October 2012 and all patients were selected from the outpatient clinic of the orthodontic department; Faculty of Dentistry, Suez Canal University, Ismailia, Egypt. The study protocol was approved by the Institutional Review Board of Suez Canal university, Ismailia, Egypt. The mean age of patients was 19 years old ranging from (14-24 years). Inclusion criteria were the presence of transverse maxillary constriction with posterior crossbite or collapsed arch requiring maxillary expansion, minimum age was 14 years old at the beginning of treatment. Exclusion criteria were craniofacial abnormality, 
Egyptian

Orthodontic Journal

presence of medical conditions which may interfere with surgery, and having orthodontic appliances prior to the start of maxillary expansion. Adequate records were collected before treatment which are dental and medical history, photos, casts, CBCT, and signed informed consent. Ten patients (two males and eight females) with a mean age of $19.3 \pm 2.91$ years were subjected to alveolar corticotomy 1week before SME, and 6 patients (two males and four females)with a mean age of $18.1 \pm 3.76$ years had SME only. Coricotomy was done in the first group as a selective buccal alveolar corticotomy from the first premolar to the first molar mesial, distal, and apical) bilaterally according to the technique described by Murphy et al. ${ }^{[16]}$ (Figure1). Each patient had CBCT images taken prior to orthodontic treatment (T1) and immediately after the completion of maxillary expansion (T2) using Hygienic banded expansion appliances. Patients were instructed to turn the screw 3 times per week with $1 / 4 \mathrm{~mm}$ change per turn until an adequate amount of overexpansion achieved evaluated by clinical observation when the lingual cusps of upper molars become in touch with buccal cusps of lower molars, then the appliance was replaced by a Trans Palatal Arch (TPA) with extended arms for at least 3 months after expansion for retention. Orthodontic treatment was continued with a full bonded straight wire preadjusted appliance (Figure2(a), (b), (c), (d)).

Imaging Device: Imaging was carried out by Cranex 3D X-ray machine (Soredex, Tuusula, Finland) at $85 \mathrm{kVp}, 15 \mathrm{~mA}, 6 \mathrm{FOV}$, and $12.6 \mathrm{~s}$.

Image Manipulation: The images were reconstructed by the special software program of Cranex 3D X-ray machine named On Demand 3D software (Build 1.0.9.1332, Cybermed, Seoul, Korea), with this software it is possible to view the different cuts at increasing magnifications for better accuracy. To evaluate the immediate dental and alveolar changes following SME, linear $(\mathrm{mm})$ and angular measurements (degrees) were taken at $\mathrm{T} 1$ and $\mathrm{T} 2$.

\section{1- Linear Measurements:}

Palatal expansion at the maxillary first molars and first premolars was measured on 3D reconstructed occlusal image and the following measurements were recorded. 
- Intermolar Width (IMW): Measured as a straight line joining the mesiobuccal cusps tips of the first molars (Figure 3(a)).

- Interpremolar Width (IPmW): Measured as a straight line joining the buccal cusps tips of first premolars (Figure 3(a)).

Two-dimensional coronal images were created perpendicular to the midsagittal plane to measure the buccal bone thickness in molar and premolar areas.

- Buccal Bone Thickness(BBT):Buccal bone measurements of the maxillary first molars and first premolars were measured from root surface to the outer most margin of buccal bone at the level of their trifurcation and bifurcation points, respectively (Figure 3(b)).

\section{2-Angular Measurements:}

Two-dimensional coronal images were created perpendicular to the midsagittal plane to measure.

- Root Angulation (RA):Measured the angle buccolingually created by a line connecting the palatal causp tips and root apices of molars and premolars (long axis) to the midsagital plane(Figure 3(c)) .

\section{STATISTICAL ANALYSIS}

$\mathrm{T} 1$ and $\mathrm{T} 2$ data were tabulated and statistical analysis was carried out using SPSS software (SPSS, 2008). Means and standard deviations were calculated for each parameter. Paired t-test (SPSS, analyze, compare means, and dependent-samples t-test) was used to test the effect of treatment on different parameters within each group $(\mathrm{P} \leq 0.05)$. Student t-test (SPSS, analyze, compare means, independent-samples ttest) was used to test the effect of different parameters between groups. To test intraexaminer reliability, 10 patient records at $\mathrm{T} 1$ and $\mathrm{T} 2$ were randomly selected and all measurements were repeated and intraclass correlation coefficients (ICCs) were calculated. 


\section{Egyptian}

Orthodontic Journal
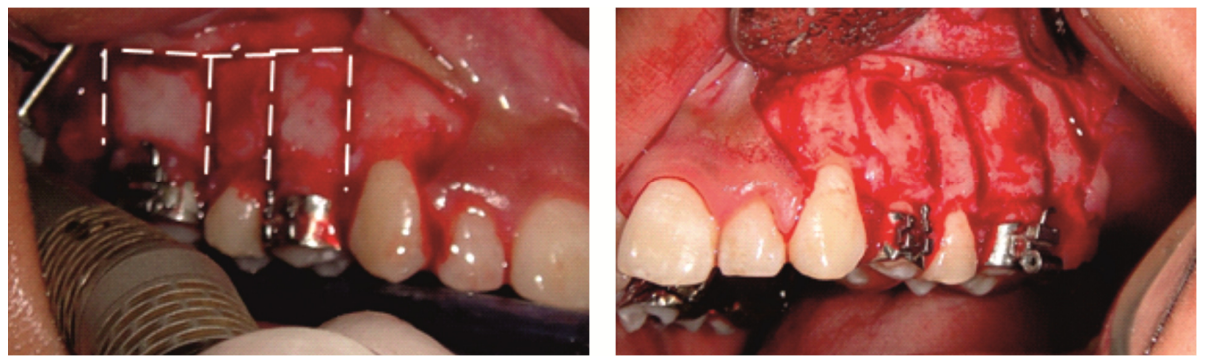

Figure 1: Corticotomy
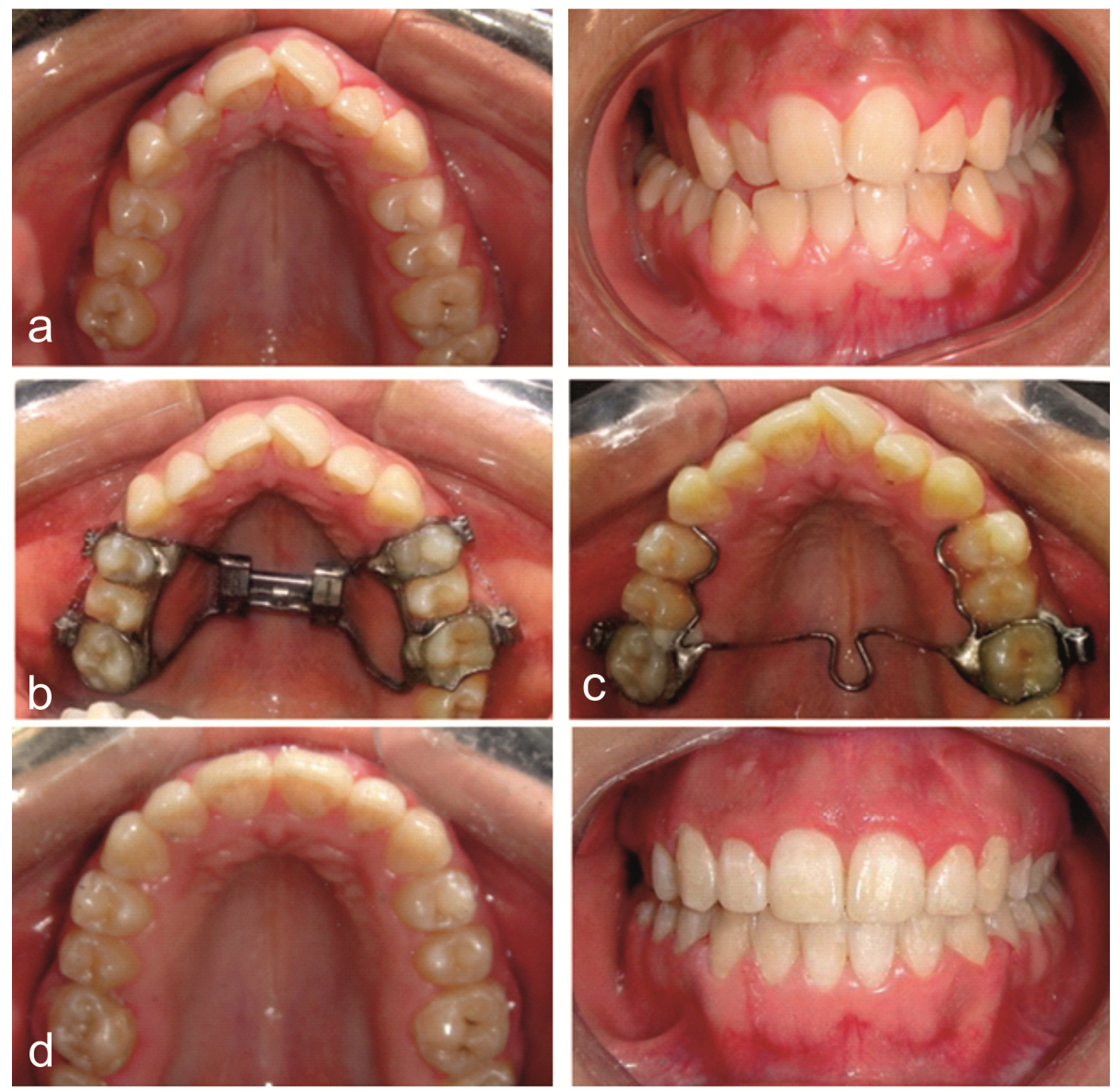

Figure 2: a: Preoperative, b: HYRAX appliance, c: TPA with extended arms, d: Postoperative

Volume 46 - December 2014 

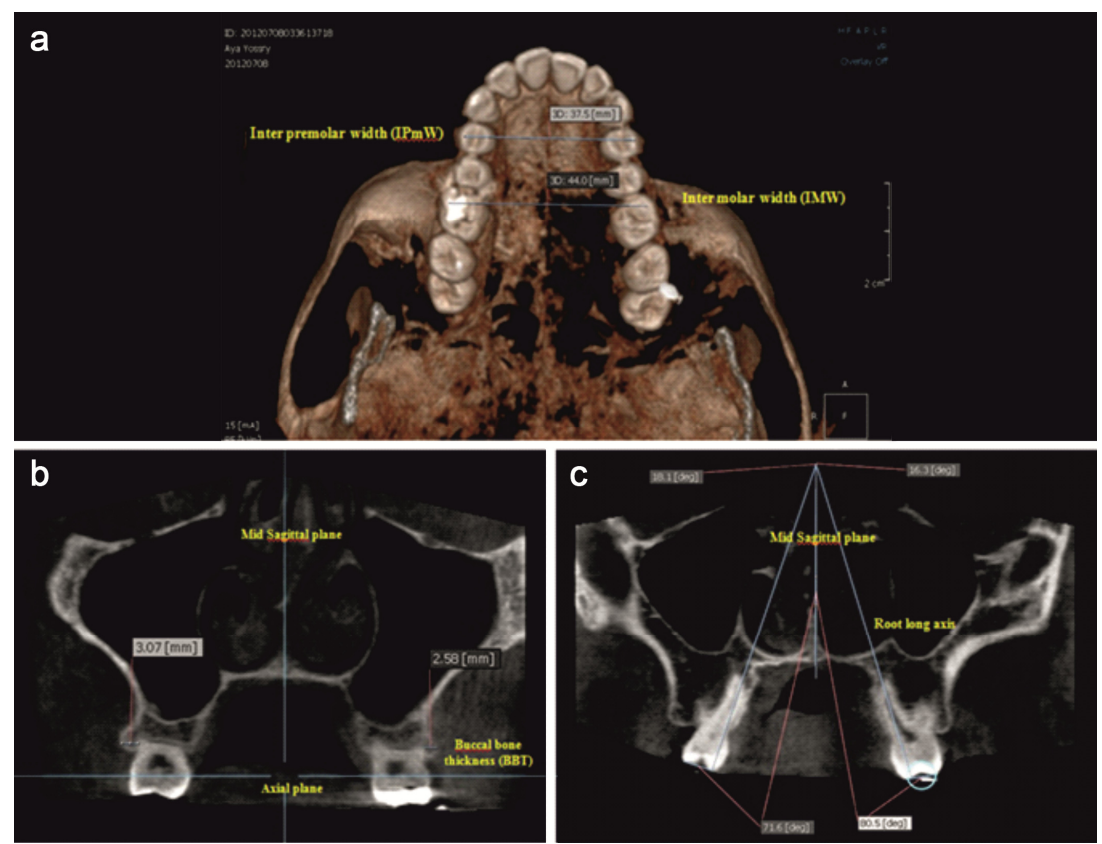

Figure 3: a: Intermolar width (IMW), b: Buccal bone thickness (BBT), c: Root angulation (RA)

\section{RESULTS}

ICC was high ranging from 0.85 to 0.99 with a mean $95 \%$ confidence interval $(\mathrm{CI})$ of 1.00 .

The effect of treatment within both groups is shown in Tables 1 and 2 and the effect of treatment between both groups is shown in Table 3.

\section{A. Linear Measurements}

\section{Expansion Effect}

Paired t-test $(\mathrm{P} \leq 0.05)$ showed statistically significant increase in IMW and IPmw between $\mathrm{T}_{1}$ and $\mathrm{T}_{2}$ time points in corticotomy and control groups. Corticotomy group showed significant increase in IMW about $5.900 \pm 0.348 \mathrm{~mm}$ and $\mathrm{IPmW}$ increase was $5.000 \pm 0.258 \mathrm{~mm}$. These values were larger than the values in the control group by $(2.4 \mathrm{~mm})$ in IMW and $(1.7 \mathrm{~mm})$ in IPmW. 


\section{Change in Buccal Bone}

Paired t-test $(\mathrm{P} \leq 0.05)$ showed statistically significant decrease in BBT between $T_{1}$ and $T_{2}$ time points in the corticotomy group, the decrease in average molar BBT was $-0.800 \pm 0.200 \mathrm{~mm}$, and in average premolar the decrease in BBT was $-0.700 \pm 0.153 \mathrm{~mm}$. Student t-test showed statistically insignificant differences in BBT change between control and corticotomy groups except for left premolars.

\section{B. Angular Measurements}

\section{Palatal Root Tipping}

Paired t-test $(\mathrm{P} \leq 0.05)$ showed statistically significant increase in RA between $T_{1}$ and $T_{2}$ time points in the corticotomy group except left premolar. Also, student t-test showed statistically insignificant differences in RA change between control and corticotomy groups in all teeth.

Table 1: Effect of treatment within control group

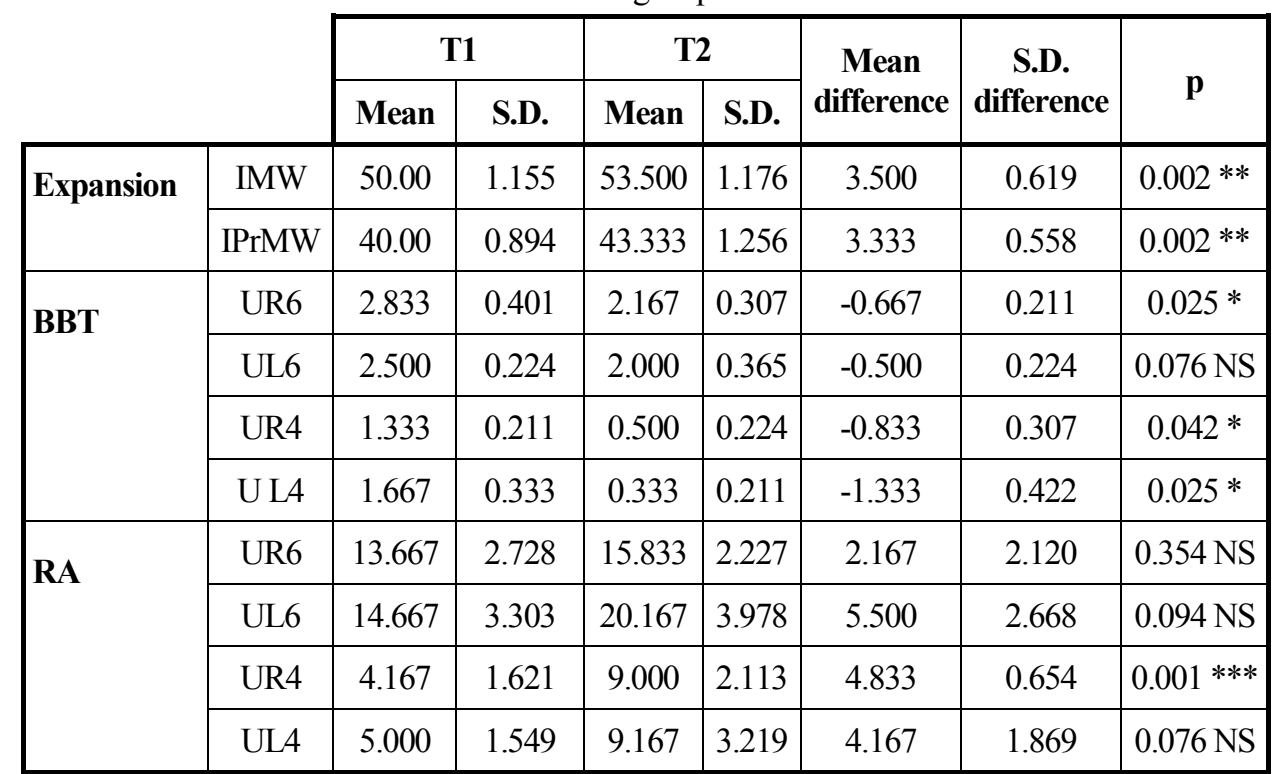

S.D. $=$ Standard deviation.

$\mathrm{P}=$ Probability level for the effect of treatment (paired $\mathrm{t}$ ).

NS = Insignificant $(\mathrm{P}>0.05)$

$*=$ Significant at $\mathrm{p} \leq 0.05$

** $=$ Significant at $\mathrm{p} \leq 0.01$

$* * *=$ Significant at $\mathrm{p} \leq 0.001$

Volume 46-December 2014 
Egyptian

Orthodontic Journal

Table 2: Effect of treatment within corticotomy group

\begin{tabular}{|c|c|c|c|c|c|c|c|c|}
\hline & & \multicolumn{2}{|c|}{$\mathbf{T 1}$} & \multicolumn{2}{|c|}{$\mathbf{T 2}$} & \multirow{2}{*}{$\begin{array}{c}\text { Mean } \\
\text { difference }\end{array}$} & \multirow{2}{*}{$\begin{array}{c}\text { S.D. } \\
\text { difference }\end{array}$} & \multirow{2}{*}{$\mathbf{p}$} \\
\hline & & Mean & S.D. & Mean & S.D. & & & \\
\hline \multirow{2}{*}{ Expansion } & IMW & 44.90 & 0.640 & 50.800 & 0.611 & 5.900 & 0.348 & $0.001 * * *$ \\
\hline & IPrMW & 37.60 & 0.400 & 42.600 & 0.400 & 5.000 & 0.258 & $0.001 * * *$ \\
\hline \multirow[t]{4}{*}{ BBT } & UR6 & 3.10 & 0.180 & 1.900 & 0.277 & -1.200 & 0.291 & $0.003 * *$ \\
\hline & UL6 & 2.80 & 0.249 & 2.000 & 0.211 & -0.800 & 0.200 & $0.003 * *$ \\
\hline & UR4 & 1.30 & 0.153 & 0.800 & 0.249 & -0.500 & 0.167 & $0.015 *$ \\
\hline & U L4 & 1.40 & 0.163 & 0.900 & 0.233 & -0.500 & 0.224 & 0.050 * \\
\hline \multirow{4}{*}{$\mathbf{R A}$} & UR6 & 15.40 & 0.846 & 21.700 & 1.491 & 6.300 & 1.257 & $0.001 * * *$ \\
\hline & UL6 & 16.40 & 0.933 & 21.500 & 0.719 & 5.100 & 1.027 & $0.001 * * *$ \\
\hline & UR4 & 5.00 & 0.978 & 11.000 & 2.821 & 6.000 & 2.113 & $0.019 *$ \\
\hline & UL4 & 4.10 & 0.948 & 8.200 & 1.948 & 4.100 & 2.238 & $0.100 \mathrm{NS}$ \\
\hline
\end{tabular}

S.D $=$ Standard deviation.

$\mathrm{P}=$ Probability level for the effect of treatment (paired $\mathrm{t}$ ).

$\mathrm{NS}=$ Insignificant $(\mathrm{P}>0.05)$

* = Significant at $\mathrm{p} \leq 0.05$

$* *=$ Significant at $\mathrm{p} \leq 0.01$

$* * *=$ Significant at $\mathrm{p} \leq 0.001$

Volume 46 - December 2014 
Egyptian

Orthodontic Journal

Table 3: Effect of treatment between control and corticotomy groups

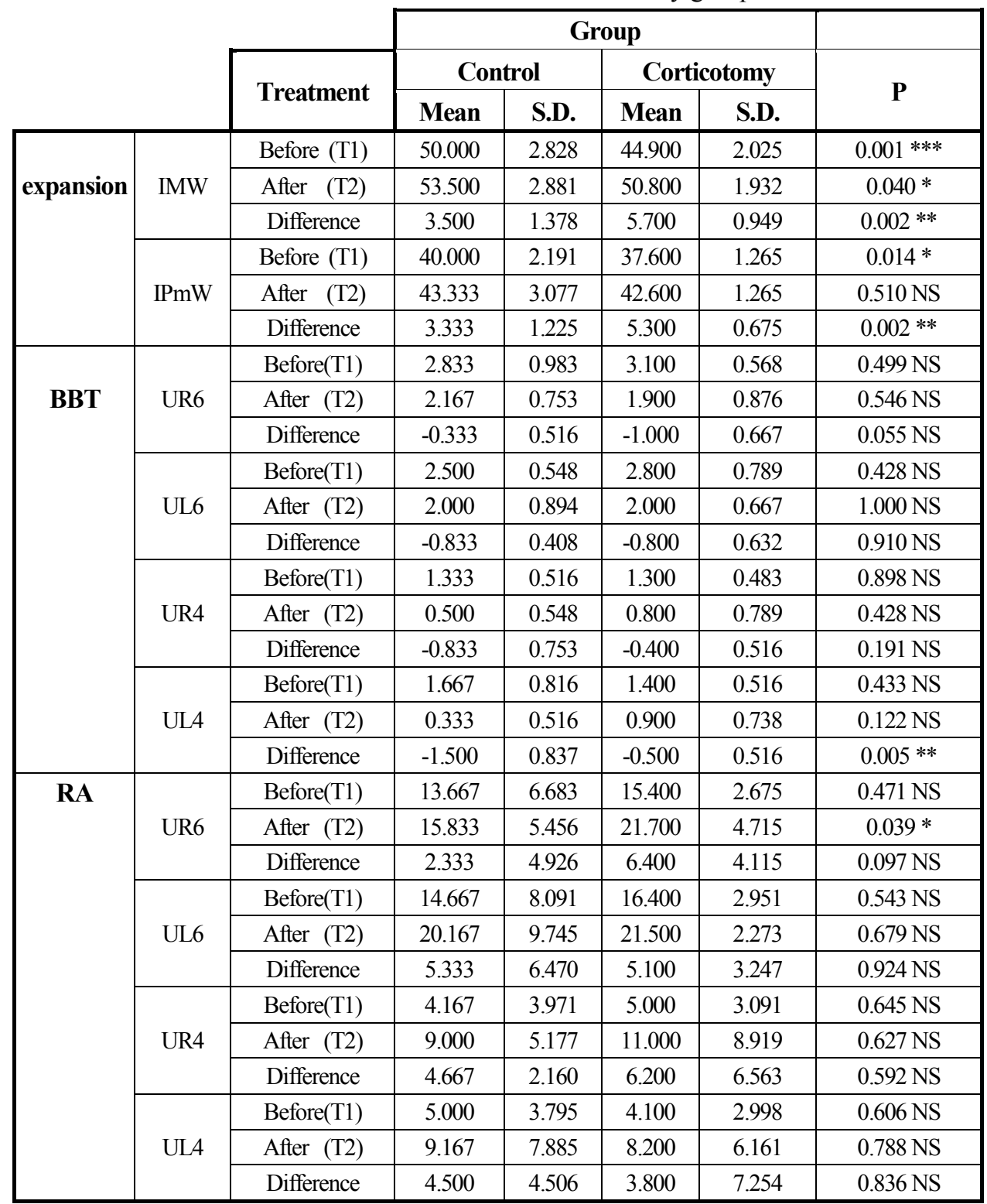

S.D. = Standard deviation. $\quad \mathrm{P}=$ Probability level for the effect of group (Student $\mathrm{t}$ test).

$\mathrm{NS}=$ Insignificant $(\mathrm{P}>0.05) *=$ Significant at $\mathrm{p} \leq 0.05$

$* * *=$ Significant at $\mathrm{p} \leq 0.00$

Volume 46-December 2014 
Egyptian

Orthodontic Journal

\section{DISCUSSION}

The aim of the current study was to evaluate dentoalveolar changes occurring with corticotomy assisted slow maxillary expansion.

There were statistically significant differences in IMW and IPmW between $T_{1}$ and $T_{2}$ time points in SME only and corticotomy groups. Corticotomy group showed an increase in IMW about $5.900 \pm 0.348 \mathrm{~mm}$ and the IPmW increase was $5.000 \pm 0.258 \mathrm{~mm}$, these values were larger than the values in SME only group by $(2.4 \mathrm{~mm})$ in IMW and $(1.7 \mathrm{~mm})$ in IPmW. These results show the effect of corticotomy in enhancing the efficiency of expansion due to RAP and are in accordance with results published from Mossaz et al. ${ }^{[14]}$ who treated unilateral crossbite with corticotomy in the affected side and found that the operated side showed more than twice the amount of skeletal expansion than the non-operated side. In SME only group, the increase in IMW was $3.500 \pm 0.619 \mathrm{~mm}$ and in IPmW was $3.333 \pm 0.558 \mathrm{~mm}$, these results were in agreement with Akyalcin et al. ${ }^{[17]}$, who showed that the IMW increased an average of $3.95 \mathrm{~mm}$ after expansion. On other hand, the amount of expansion in corticotomy group was larger than that of Domann CE et al. ${ }^{[18]}$, who found that the expansion achieved after RME was $4.7788 \pm 2.8474 \mathrm{~mm}$ for IPmW and $4.6943 \pm 3.2198 \mathrm{~mm}$ for IMW.It is important to mention that the studies whose results are different in IMW and IPmW values were done in samples with younger mean age and with different methodology producing skeletal and dentoalveolar expansion rather than only dentoalveolar expansion produced in our study.

In the present study, the buccal bone change in corticotomy group showed that the decrease in the average molar BBT was $-0.800 \pm 0.200 \mathrm{~mm}$ and in the average premolar the decrease in BBT was $-0.700 \pm 0.153 \mathrm{~mm}$. The results of our study were not different from the results concluded by Garib et al. ${ }^{[19]}$ who showed that the buccal bone plate thickness decreases between 0.6-0.9 mm during rapid expansion, and Domann CE et al. ${ }^{[18]}$ who found that the thickness of the buccal bone decreased on all observed roots connected to Hyrax after RME, the decrease was 
Egyptian

Orthodontic Journal

about $-0.73 \mathrm{~mm}$ in $\mathrm{BBT}$ of molars but the decrease in premolar BBT was -0.35 in premolars. Also, our results were in accordance with Pangrazio-Kulbersh et al. ${ }^{[20]}$ who found that the amount of bone lost after RME was $-0.59 \mathrm{~mm}$ (MRt), $-0.72 \mathrm{~mm}$ (PMRt), -0.50 mm (MLft), and $-0.57 \mathrm{~mm}$ (PMLft).In our study, the student $t$-test showed statistically insignificant differences in BBT change between SME only and corticotomy groups except for left premolars. These results indicated that the corticotomy did not affect the amount of buccal bone loss during the expansion procedure despite of not using a bone graft. The buccal bone regeneration after expansion was not measured in this study, but it was anticipated as Akyalcin et al. ${ }^{[17]}$ compared the effect of maxillary expansion on the buccal plate of the maxillary first molars and maxillary first premolars, and found that the decrease between $\mathrm{T}_{1}$ (before) and $\mathrm{T}_{2}$ (after) was observed for all the teeth and an increase between $T_{2}$ and $T_{3}$ (2-3 years after expansion)was found in the buccal bone thickness.

In our study, significant increase of root tipping in corticotomy group in average molar root angulations was $5.600 \pm 0.267^{\circ}$, in average premolar the increase in root angulations was $5.200 \pm 1.373^{\circ}$.Our results were comparable to the results published by Christie et al ${ }^{[21]}$ who found that the average of buccal tipping of the molars with a bonded Haas expander was $5.91^{\circ}$, and Domann CE et al. ${ }^{[18]}$ who evaluated the immediate effects of RME with Hyrax appliances on the dentoalveolar complex and found a significant tipping of the palatal roots of the maxillary right and left premolars (Rt premolar $5.737^{\circ} / \mathrm{Lt}$ premolar $7.637^{\circ}$ ) and maxillary right and left molars (Rt molar $1.168^{\circ} / \mathrm{Lt}$ molar $1.925^{\circ}$ ). In the present study, student $t$-test showed statistically insignificant differences in root angulation change between SME only and corticotomy groups in all teeth. These results showed that the greater expansion gained in corticotomy group was due to dentoalveolar expansion rather than dental tipping. The corticotomy initiated RAP which is characterized by an increase in cortical bone porosity because of increased osteoclastic activity and physiologic events such as calcium depletion and diminished bone densities occurred according to Yaffe et al. ${ }^{[13]}$, decreased cortical bone density following the corticotomy leads to gain more expansion with non-significant increase in root tipping . 
Egyptian

Orthodontic Journal

\section{CONCLUSIONS}

1. Corticotomy assisted SME is considered a safe and efficient technique to increase transverse maxillary dimensions.

2. Corticotomy assisted expansion showed significant increase in arch widths (IMW and IPmW)compared to SME only group.

3. Corticotomy assisted SME showed significant decrease in buccal bone thickness of all teeth attached to the appliance.

4. No significant difference in BBT change between both groups except left premolars, and corticotomy did not affect the amount of buccal bone loss during the expansion procedure despite of not using a bone graft.

5. Significant increase of RA occurred in corticotomy group except the left premolars.

6. No significant differences in RA were found between both groups suggesting that the greater expansion gained in corticotomy group was due to dentoalveolar expansion rather than dental tipping.

\section{REFERENCES}

1. Haas A.J. Palatal expansion: Just the beginning of dentofacial orthopedics. Am J Orthod 1970; 57:219-255.

2. Bishara S. E. and Staley R. N. Maxillary expansion: Clinical implications. Am J Orthod Dentofacial Orthop 1987; 91:3-14.

3. Harvold E. P., Chierici G., and Vargervik K. Experiments on the development of dental malocclusions. Am J Orthod 1972; 61:38-44.

4. Bell R. A. A review of maxillary expansion in relation to rate of expansion and patient's age. Am J Orthod 1982; 81:32-37.

5. Baccetti T., Franchi L., Cameron C. G., and McNamara J. A. Jr., Treatment timing for rapid maxillary expansion. Angle Orthod. 2001; 71(5):343-50. 
6. Melsen B. Palatal growth studied on human autopsy material. A histologic microradiographic study. Am J Orthod 1975; 68:42-54.

7. Lokesh Suria and Parul Tanejab. Surgically assisted rapid palatal expansion: A literature review. Am J Orthod Dentofacial Orthop 2008; 133:290-302.

8. Vanarsdall R. L. Jr. Transverse dimension and long-term stability. Semin Orthod1999; 5:171-180.

9. Köle H. Surgical operations of the alveolar ridge to correct occlusal abnormalities. Oral Surg Oral Med Oral Pathol 1959; 12:515-529.

10. Wilcko W. M., Wilcko T., Bouquot J. E., and Ferguson D. J. Rapid orthodontics with alveolar reshaping: two case reports of decrowding. Int J Periodontics Restorative Dent 2001; 21:9-19.

11. Wilcko M. T., Bissada W. W., and Nabil F. An Evidence-Based Analysis of Periodontally Accelerated Orthodontic and Osteogenic Techniques: A Synthesis of Scientific Perspectives. Semin Orthod 2008; 14:305-316.

12. Frost H. M. The regional accelerated phenomenon. Orthop Clin $\mathrm{N}$ Am1981;12:725-726.

13. Yaffe A., Fine N., and Binderman I.: Regional accelerated phenomenon in the mandible following mucoperiosteal flap surgery. J Periodontol 1994, 65:79-83.

14. Mossaz C. F., Byloff F. K., and Richter M. Unilateral and bilateral corticotomies for correction of maxillary transverse discrepancies. Eur J Orthod 1992; 14 (2): 110-116.

15. Hassan A. H., AlGhamdi A. T., Al-Fraidi A. A., Al-Hubail A., and Hajrassy M. K.: Unilateral cross bite treated by corticotomy assisted expansion: two case reports. Head \& Face Medicine 2010; 6:6.

16. Murphy K. G., Wilcko M. T., Wilcko W. M., and Ferguson D. J. Periodontal accelerated osteogenic orthodontics: a description of the surgical technique. J Oral Maxillofac Surg 2009; 67:2160- 2166. 
17. Sercan Akyalcin, Jeffrey S. Schaefer, Jeryl English, Claude R. Stephens, and Sam Winkelmann. A cone-beam copmuted tompgraphy evaluation of buccal bone thickness following maxillary expansion.. Imaging Sci Dent. 2013 June; 43(2): 85-90.

18. Domann C. E.,Kau C. H., English J. D., Xia J. J., Souccar N. M., and Lee R. P. Cone beam computed tomography analysis of dentoalveolar changes immediately after maxillary expansion. Orthodontics (Chic.). 2011 Fall; 12(3):202-9.

19. Garib D. G., Henriques J. F., Janson G., Roberto de Freitas M. R., and Fernandes A. Y. Periodontal effects of rapid maxillary expansion with tooth-tissue-borne and tooth-borne expanders: A computed tomography evaluation. Am J Orthod Dentofacial Orthop 2006; 129:749-58.

20. Valmy Pangrazio-Kulbersh, Brynn Jezdimir, Mariana de Deus Haughey, Richard Kulbersh, Paul Winee, and Richard Kaczynski. CBCT assessment of alveolar buccal bone level after RME. Angle Orthod.2013; 83:110-116.

21. Christie K. F., Boucher N., and Chung C. H. Effects of bonded rapid palatal expansion on the transverse dimensions of the maxilla: A cone-beam computed tomography study. Am J Orthod Dentofacial Orthop 2010; 137:S79-85. 